\title{
Lunabotics Mining Competition: Inspiration through Accomplishment
}

\author{
R. P. Mueller ${ }^{1}$
}

${ }^{1}$ National Aeronautics \& Space Administration (NASA), Surface Systems Office, M/S: NE-S, Kennedy Space Center, KSC, FL 32899, USA, 321-867-2557; email: rob.mueller@nasa.gov

\section{ABSTRACT}

Space Mining for resources such as water ice, and regolith, which contain many elements in the form of metals, minerals, volatiles and other compounds, is a necessary step in Space Resource Utilization. One of the primary goals is to extract propellants from the regolith such as oxygen and hydrogen which could then be used for in-space transportation. In addition, the space mining system can be used for various construction tasks that can benefit human and robotic exploration as well as scientific investigations based on the exposed topography.

The National Aeronautics \& Space Administration (NASA) Lunabotics Mining Competition is a university-level competition designed to engage and retain students in science, technology, engineering and mathematics (STEM). NASA will directly benefit from the competition by encouraging the development of innovative lunar excavation concepts from universities which may result in clever ideas and solutions which could be applied to an actual lunar excavation device or payload. The challenge is for students to design and build a remote controlled or autonomous excavator, called a lunabot, that can collect and deposit a minimum of 10 kilograms of lunar simulant within 15 minutes. The complexities of the challenge include the abrasive characteristics of the lunar simulant, the weight and size limitations of the lunabot, and the ability to control the lunabot from a remote control center or operate autonomously.

This paper will present an update of the results and lessons learned during the first and second annual Lunabotics Mining Competitions held in May 2010 and May 2011. It will also preview the 2012 competition with a review of the revised rules. In 2010, 22 United States (US) universities competed, and in May 2011 the competition was opened to international participation. In 2011, 36 teams actually competed from 26 USA states and 4 foreign countries (India, Bangladesh, Colombia and Canada). This combined total directly inspired an estimated 653 university students. In 2012 more students and the public will be engaged via internet broadcasting and social networking media. The various designs will be cataloged and categorized to provide information to future Lunabotics mining robot designers and competitors. It is also expected to be of value for actual future space missions, as knowledge is gained from testing many innovative prototypes in simulated lunar regolith. 


\section{INTRODUCTION}

In 2005 the United States of America congress funded a program of contests to stimulate innovation and competition in technical areas of interest to NASA. This program consists of the NASA Centennial Challenges, a collection of public contests designed to stimulate technological innovation in areas that benefit space exploration. The intent was to build on historic and current prize experience. As early as the 18th century, the British government offered the Longitude Prize, a competition for a navigational solution to the accurate determination of longitude on the high seas. At the time the prize was set, it was assumed that the solution laid in using star maps as navigational aids and that the winner would be an astronomer. The solution was actually achieved by a London clockmaker and his invention, the marine chronometer [6]. Another historic prize was the $\$ 25,000$ Orteig Prize which was offered in 1919 by a prominent New York businessman, Raymond Orteig, for the first non-stop flight from New York to Paris. It was won in May, 1927 by Charles Lindbergh and is widely credited with stimulating public interest in commercial passenger flights and bolstered confidence in airplane safety. More recently the Ansari X PRIZE was a space competition in which the X PRIZE Foundation offered a US $\$ 10,000,000$ prize for the first non-government organization to launch a reusable manned spacecraft into space twice within two weeks. The prize was won on October 4, 2004, the 47th anniversary of the Sputnik 1 launch, by a project designed by Burt Rutan and financed by Microsoft co-founder Paul Allen, using the experimental space plane Space Ship One. \$10 million was awarded to the winner, but more than $\$ 100$ million was invested in new technologies in pursuit of the prize.

NASA Centennial Challenges: Regolith Excavation. Prize competitions have been used throughout history to accelerate the development of many different technologies. The desire for new or better technologies have often come from unmet needs in various sectors of society, including commerce, industry, military, public safety, public health, and adventure/tourism.

The history of successful prize competitions has shown the potential for break-through developments and the accomplishment of feats thought to be "impossible." In most cases, the detrimental effects are negligible for a competition when the prize is not won, because there was little cost and no resulting purse payment.

Although the U.S. government has a long history of awarding medals to individuals of merit (a.k.a. 'recognition prizes'), it has only recently begun experimenting with inducement prizes to spur technology developments in selected areas. Centennial Challenges is a program recently initiated at the National Aeronautics and Space Administration. In the case of NASA contracts and grants, the government will pay $100 \%$ of the cost proposed by the contract winner. In some cases, the government will pay more than $100 \%$ of the contract cost due to any number of factors or circumstances. In the case of prizes, the prize purse is generally some fraction of what 
a contract would be worth to achieve the same results. Also, the government only makes a payment after somebody wins the competition by meeting all requirements as described in the rules. [1]

Regolith Excavation Challenge: 2007. The first NASA competition related to excavating lunar regolith simulant was organized by the California Space Education and Workforce Institute (CSEWI) and the California Space Authority (CSA) as partner organizations to NASA (Everingham, 2008). This event was held in Santa Maria, California from May 11-12, 2007, with a prize of $\$ 250,000$ offered to the competitor that excavated the most simulated lunar regolith and deposited it in a collection box. The lunar regolith simulant used was 8 tons of JSC-1a, which is widely used for NASA lunar research activities. In this challenge, teams designed and built robotic machines to excavate simulated lunar soil (regolith). Excavating regolith will be an important part of any construction projects or processing of natural resources on the Moon (Mueller, 2007). The robots were tested in a box, containing eight tons of JSC-1a simulated lunar regolith, that is about 4 meters square and about one-half meter deep. In order to qualify for a prize, a robot had to dig up and then dump at least $150 \mathrm{~kg}$ of regolith into a container in 30 minutes. The teams with the robots that moved the most regolith could claim the three cash prizes. NASA is looking for new ideas for excavation techniques that do not require excessively heavy machines or large amounts of power. The competition required autonomous robots with a simulated wireless signal time delay of several seconds simulating lunar communications. There were four teams of engineers competing to be the first to build a robot capable of collecting at least $150 \mathrm{~kg}$ of lunar soil in less than 30 minutes. Machines also could use only 30 watts of power, which was provided by a "house" tether and had to weigh less than 40 $\mathrm{kg}$ as they excavated the simulated lunar regolith defeated the competitors. Two other teams dropped out before even landing at the competition [6]. Three of the four teams had excavators that shut down due to mechanical or electrical challenges from digging. The "Technology Ranch" team, however, was the exception delivering 65.25 kilograms within the half hour requirement - a clear accomplishment but still far below the 150 kilograms needed to win.

Teams from Rancho Palos Verdes, Calif., Livermore, Calif., Berkeley, Calif., Fulks Run, Va., Rolla, Mo., Berkley, Mich., Milwaukee, and Vancouver, British Columbia, registered to participate in the challenge. The teams that actually competed were:

- Technology Ranch, Pismo Beach -65.25 kg excavated

- The Lunar Miners, University of Missouri-Rolla -Broke down while digging.

- Duplex Engineering, Michigan, Geoffrey Pulk - Broke down while digging.

- Todd Mendenhall, Mendenhall BFD excavator - Broke down while digging. 
Regolith Excavation Challenge: 2008. The 2008 Regolith Excavation Challenge was held on Aug. 2 and 3 on the campus of the California Polytechnic State University in San Luis Obispo, CA. The 2008 prize purse was $\$ 750,000$, and the rules were not changed significantly from 2007, but mass allowed was increased to $70 \mathrm{~kg}$ and the available tethered power was increased to 150 watts. In addition a 20 degree inclination (from horizontal) ramp was provided to all the teams. Twenty-five teams registered for the competition. Sixteen teams came to San Luis Obispo, at the Cal Poly Campus, to compete and although no team was able to win the prize, the competition was very spirited. The challenge was significantly more difficult than the 2007 event. To autonomously navigate through randomly placed rocks and to reach a collection box at the top of a ramp proved to be a taxing technical challenge for all of the entrants. The task required expert integration of multiple systems and thorough testing of complex operational scenarios. Following the competition phase of the event, many of the teams did demonstrate their excavators under less demanding conditions and some were able to deliver loads of regolith to the collection box. No cash prizes were awarded but the judges selected three teams for recognition. Tech Ranch, Slobotics, and Team Waldbaum were designated for first, second and third prize, respectively. The competitors included several universities, small businesses and a few individuals. NASA engineers from six different field centers plus Headquarters witnessed the event. During a break, Astronaut Jim Newman addressed the assembled competitors and spectators. (NASA, 2008). Eight teams actually put their inventions to the test during the competition at Cal Poly, but none met the challenge of digging $150 \mathrm{Kg}$ of simulated moon dirt, called regolith, putting it into a collector and completing the task within 30 minutes. In total, 25 teams registered for the event, but only 16 traveled to the Central Coast. Half of those ended up dropping out due to mechanical or logistical problems. Two teams from San Luis Obispo County competed along with others from elsewhere in California, Texas, Washington, Colorado and Michigan [6]. The final teams to compete were:

- Waldbaum, Sunnyvale, CA

- Next Step, Houston, TX

- Tech Ranch, Arroyo Grande, CA

- LuneOreDiggers, Denver, CO

- Cal Poly Slobotics, San Luis Obispo, CA

- Team of One, Detroit, MI

- Toy Garden, Friday Harbor, WA

- Boppers, Huntington Beach, CA 
Regolith Excavation Challenge: 2009. For the 2009 challenge, two significant changes were made to the rules. First, teams were allowed to tele-operate their robots instead of requiring them to be fully autonomous as in previous years. The team's drivers were isolated in a room separate from the robot and field and had to control their robot through a competition-provided two-second delay on the sending and receiving of commands. This was designed to simulate delayed communication to the moon. Teams were limited to $1000 \mathrm{kbs}$ communication bandwidth averaged over their 30-minute run. Second, competitors were required to provide their own onboard power. In previous competitions, robots were tethered to a competition power source that limited them to 30 watts in 2007 and 150 watts in 2008. To account for the onboard power requirement, the weight limit was increased from $70 \mathrm{~kg}$ to $80 \mathrm{~kg}$. Optional ramps were allowed but had to be provided by the teams.

Twenty-five teams registered for the challenge and traveled from across the country to compete. Of the 23 teams, only 19 competed, one was disqualified as a result of specification violations and the rest withdrew on their own due to last-minute mechanical or logistical problems. These teams pushed their robotic competitors to the limit and three teams claimed a total of $\$ 750,000$ in NASA prizes for their hard work and innovation at this year's Regolith Excavation Challenge held at NASA's Ames Research Center on Moffett Field. This was the first time in the competition's threeyear history that any teams qualified for a cash prize, the largest NASA had ever given at that time.

Paul's Robotics, a team led by college student, Paul Ventimiglia of Worcester Polytechnic Institute won the $\$ 500,000$ first prize in the 2009 Regolith Excavation Challenge that concluded on Oct. 18. The second place prize of $\$ 150,000$ was won by Terra Engineering of Gardena, California and the $\$ 100,000$ third place prize went to Team Braundo of Rancho Palos Verdes, California. Twenty teams qualified for the event that was held at the NASA Ames Research Park in Mountain View, CA. The California Space Education and Workforce Institute managed the competition. The winning excavator (Paul's Robotics, Worcester Polytechnic Institute) lifted $437 \mathrm{~kg}$ of regolith material in the allotted time. Runners up (Terra Engineering) excavated $270 \mathrm{~kg}$ and $263 \mathrm{~kg}$ (Team Braundo), respectively. Special mention was given to Team E-REX and Eric Jones of Little Rock, AR for transferring the most regolith, $75 \mathrm{~kg}$, in a single deposit of simulated lunar substance into the official collector bin. Competitors were required to use mobile, robotic digging machines capable of excavating up to at least $150 \mathrm{~kg}$ of regolith and depositing it into a container in 30 minutes or less. The rules require the remote controlled vehicles to contain their own power sources and weigh no more than $80 \mathrm{~kg}$ (CSEWI, 2009). 


\section{LUNABOTICS MINING COMPETITION OVERVIEW}

NASA's Lunabotics Mining Competition is designed to promote the development of interest in space activities and STEM (Science, Technology, Engineering, and Mathematics) fields. The competition uses excavation, a necessary first step towards extracting resources from the regolith and building bases on the moon. The unique physical properties of lunar regolith and the reduced 1/6th gravity, vacuum environment make excavation a difficult technical challenge. Advances in lunar regolith mining have the potential to significantly contribute to our nation's space vision and NASA space exploration operations.

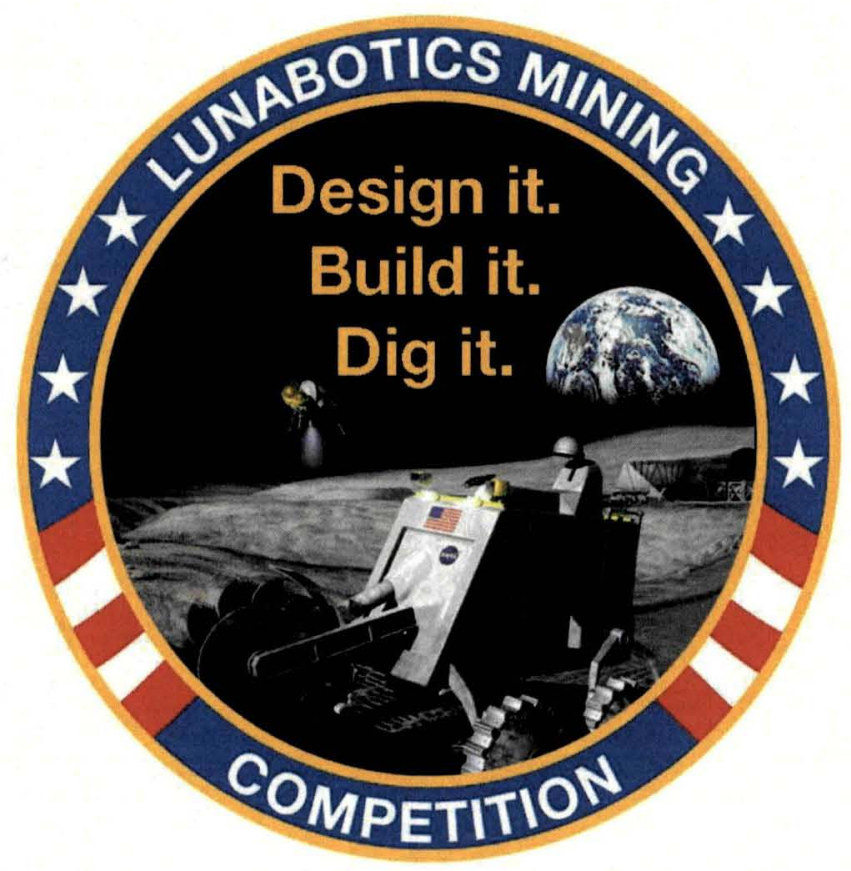

Figure 1: Lunabotics Mining Competition Logo

The competition is conducted by NASA at the Kennedy Space Center Visitor Complex. The team that can use telerobotic or autonomous operation to excavate lunar regolith simulant, called Black Point-1 or BP-1, and score the most points wins the Joe Kosmo Award for Excellence. The winning team receives the Joe Kosmo Award for Excellence trophy, KSC launch invitations, team certificates for each member, a $\$ 5,000$ team scholarship, and up to $\$ 1,000$ travel expenses for each team member and one faculty advisor to participate at one of NASA's remote research and technology 
tests. Awards for other categories included monetary team scholarships, a school trophy or plaque, team and individual certificates, and KSC launch invitations.

Undergraduate and graduate student teams enrolled in a U.S. or international college or university are eligible to enter NASA's Lunabotics Mining Competition. Design teams must include: at least one faculty with a college or university and at least two undergraduate or graduate students. NASA has not set an upper limit on team members. A team should have a sufficient number of members to successfully operate their Lunabot. Teams will compete in up to five major competition categories including: on-site mining, systems engineering paper, outreach project, slide presentation (optional), and team spirit (optional). Additionally, teams can earn bonus points for mined and deposited BP-1 in the competition attempts, having multidisciplinary teams, and collaborating between a majority institution and a U.S. minority serving institution. All documents must be submitted in English (NASA, 2011).

For more information, visit NASA's Lunabotics Mining Competition on the Web at www.nasa.gov/Lunabotics; on Facebook at www.facebook.com/Lunabotics; on YouTube at http://www.youtube.com/user/Lunabotics; and follow Lunabotics on Twitter at http://twitter.com/\#!/Lunabotics

Lunabotics Mining Competition: 2010. The Lunabotics Mining Competition (LMC) was held on May $27 \&$ 28, 2010 at the U.S. Astronaut Hall of Fame near Kennedy Space Center, FL. Twenty-two teams competed for the grand prize of winning the Joe Kosmo Award for Excellence. A total of 181 students participated in the competition, but only USA University teams were allowed to enter in 2010.

The excavation robot was designated a "Lunabot" and the mass limit was $80 \mathrm{Kg}$. An allowable average data rate of $5 \mathrm{Mb} / \mathrm{s}$ over 15 minutes of competition time was required. Each team was required to dig at least $10 \mathrm{~kg}$ of regolith simulant to qualify for the on-site mining prize attempt. The excavation hardware was required to be contained within $1.5 \mathrm{~m}$ width $\times .75 \mathrm{~m}$ length $\times 2 \mathrm{~m}$ height. The hardware could deploy beyond the $1.5 \mathrm{~m} \times .75 \mathrm{~m}$ footprint after the start of the competition attempt, but was not allowed to exceed a 2 meter height. There was no communications signal time delay and the lunabot was tele-operated from a remote control center where the operators could only see the arena through onboard or one facility camera.

Lunabotics Mining Competition: 2011. In 2011, the rules were unchanged except that international participation was allowed. This created a burst of additional interest with 60 universities registering and 36 actually competing at Kennedy Space Center. Of these 14 teams were able to excavate regolith and dump it in the collection bin. There were 36 teams from 26 states and 4 foreign countries (India, Bangladesh, Colombia and Canada) represented. 


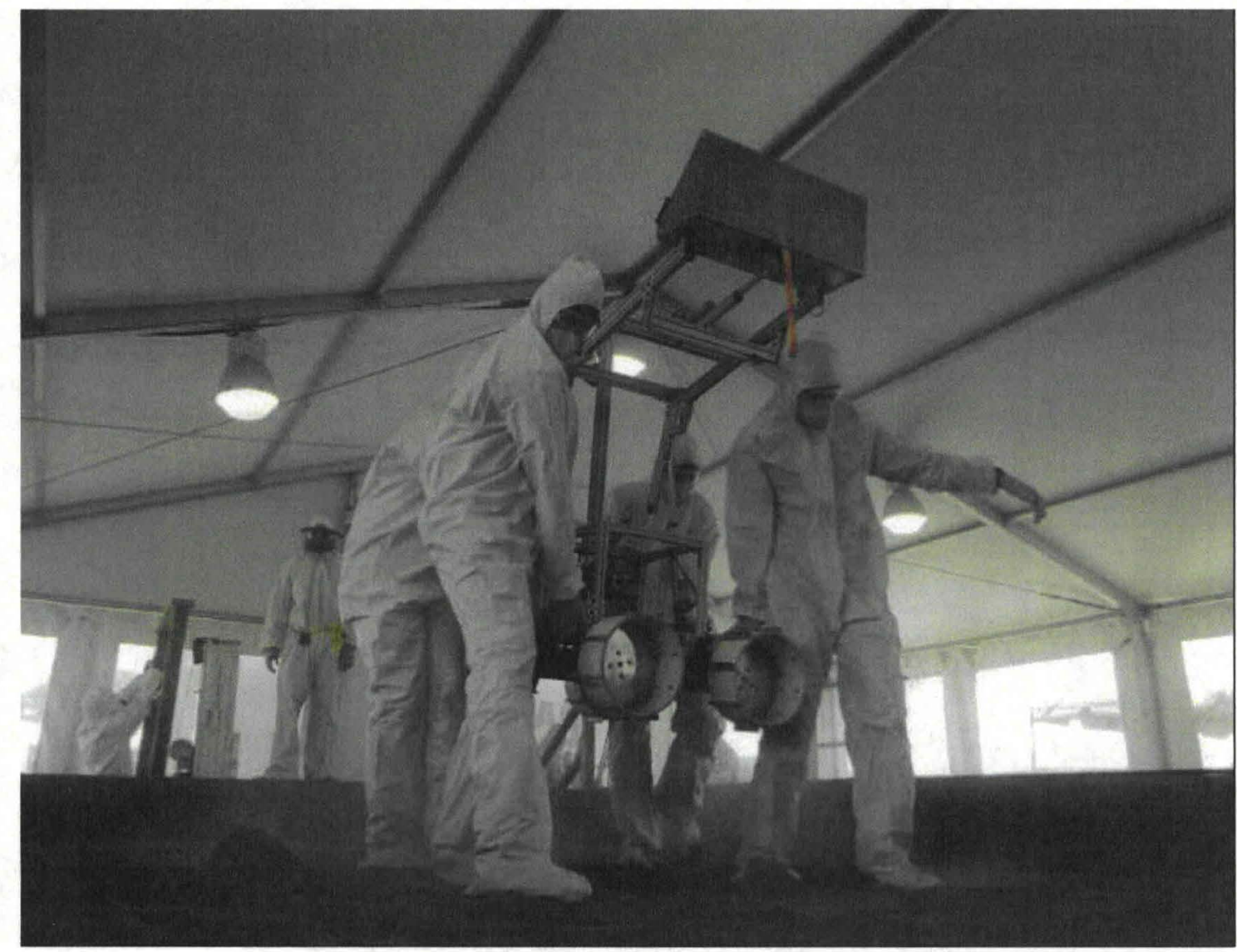

Figure 2: A Lunabot being placed in the Lunarena by its team members

\section{BENEFITS}

The biggest benefit of the Lunabotics Mining Competition is that it is a university-level competition designed to engage and retain students in science, technology, engineering and mathematics (STEM). The rapidly advancing technology development in the world is out-pacing the number of highly educated people that are needed for businesses to function in a technologically advanced society. Our sponsors (Caterpillar, inc, Newmont Mining Corp., Harris Corp and Honeybee Robotics) have all stated that they cannot find enough highly qualified people in the labor market and have a desire to support this competition so that they have a better labor force to draw from.

The Lunabotics Mining Competition inspires students and prepares them for careers in high technology that may lead to higher wages and a better standard of living.

NASA will directly benefit from the competition by encouraging the development of innovative lunar excavation concepts from universities which may result in clever ideas and solutions which could be applied to an actual lunar excavation device or payload. In addition, at Kennedy Space Center the 25' x 25' Regolith Bin will be used for new 
technologies development (In-Situ Resource Utilization \& Human Robotic Systems), when it is not being used for the competition.

The Lunabots developed may trigger new concepts for regolith excavation technologies and the related terrestrial mining and construction equipment which amounts to a very large global market worth hundreds of billions of dollars.

Community awareness of future NASA activities is promoted and stimulated by the press events associated with the competition including a large internet presence. In 2011, the Lunabotics Competition broadcast was downloaded over 500,000 times (NASA EDGE TV). Outreach to local middle schools, FIRST Robotics, Girl Scouts and Boy Scouts is actively pursued.

In addition, this event is a KSC Visitor Complex tourist attraction and educational event which enhances traffic to the visitor center and increases local economic activity.

\section{SYSTEMS ENGINEERING CAPSTONE SENIOR DESIGN PROJECT}

Most universities that enter this competition award credit to the students by making it a part of their senior design project curriculum in the final year of studies. This provides a valuable "hands-on" experience where the previous years of theoretical studies are reduced to practice by conceiving, designing, building and operating a complex mechatronic system - the Lunabot. Most students have reported this experience as being tremendously rewarding and satisfying. The Lunabot must be built by a team of students, which also teaches them the value of team work and how to handle group dynamics.

NASA designs and operates its spacecraft, ground support equipment and facilities using systems engineering principles. In order to teach these methods to the university students, a systems engineering paper is required as part of the competition, which is scored by a panel of NASA and industry experts. The NASA education department has developed a systems engineering resource for students in collaboration with Dr. David Beale at Auburn University which can be visited at:

http://education.ksc.nasa.gov/esmdspacegrant/LunarRegolithExcavatorCourse/index.ht $\mathrm{m}$

The course is called ESMD Course Material : Fundamentals of Lunar and Systems Engineering for Senior Project Teams, with Application to a Lunar Excavator, and includes information relevant to designing a lunar excavator using NASA systems engineering documentation and principles. 


\section{NASA LUNABOTICS MINING COMPETITION RULES}

In 2010/2011 Lunabotics Mining Competition rules \& specifications were based on Constellation program requirements. NASA has revised the rules for 2012 to reflect new NASA requirements. In addition, last year's winner would have placed $14^{\text {th }}$ in 2011, also necessitating changes to make the competition more challenging.

The 2012 competition will be held from May 21-26, 2012 at the Kennedy Space Center Visitor Complex. This year the scoring for the Mining Category will not be based primarily on the amount of material excavated in the allowed time but instead will require teams to consider a number of design and operation factors such as dust tolerance and projection, communications, vehicle mass, energy/power required, and level of autonomy. Each team must compete on-site at the Kennedy Space Center Visitor Complex, Florida in the United States of America on May 21-26, 2012. A minimum amount of $10 \mathrm{~kg}$ of BP-1 must be mined and deposited during each of two competition attempts according to the rules to qualify to win in this category. In the case of a tie, the teams will compete in a tie-breaking competition attempt. The judges' decisions are final in all disputes. The teams with the first, second, and third most LunaPoints averaged from both attempts will receive team plaques, individual team certificates, KSC launch invitations, $\$ 3,000, \$ 2,000$, and $\$ 1,000$ scholarships and 30, 25, and 20 points toward the Joe Kosmo Award for Excellence, respectively. Teams not winning first, second, or third place in the mining category can earn one bonus point for each kilogram of BP-1 mined and deposited up to a maximum average of ten points toward the Joe Kosmo Award for Excellence. The most innovative and lunar like design will receive the Judges' Innovation Award at the discretion of the mining judges.

In each of the two official competition attempts, the teams will score cumulative LunaPoints. See Table 1 for the Mining Category Scoring Example. The teams' ranking LunaPoints will be the average of their two competition attempts.

A) Each team will be awarded 1000 LunaPoints after passing the safety inspection and communications check.

B) During each competition attempt, the team will earn 2 LunaPoints for each kilogram in excess of $10 \mathrm{~kg}$ of BP-1 deposited in the LunaBin. (For example, $110 \mathrm{~kg}$ of BP-1 mined will earn 200 points.)

C) During each competition attempt, the team will lose 1 LunaPoint for each 50 kilobits/second $(\mathrm{kb} / \mathrm{sec})$ of average data used throughout each competition attempt. A minimum of $10 \mathrm{~kg}$ of BP-1 must be mined and deposited in the LunaBin during each competition attempt or the team will lose 100 LunaPoints, which is the maximum number of LunaPoints for this rule. (For example, $5000 \mathrm{~kb} / \mathrm{sec}$ will lose 100 points.)

D) During each competition attempt, the team will lose 10 LunaPoints for each kilogram of total Lunabot mass. (For example, a Lunabot that weighs $80 \mathrm{~kg}$ will lose 800 LunaPoints.) 
E) During each competition attempt, the team will earn 100 LunaPoints if the amount of energy consumed by the Lunabot during the competition attempt is reported to the judges after each attempt. The amount of energy consumed will not be used for scoring; a team must only provide a legitimate method of measuring the energy consumed and be able to explain the method to the judges.

F) During each competition attempt, the judges will award the team 0 to 200 LunaPoints for regolith dust tolerant design features on the Lunabot and regolith dust free operation. If the Lunabot has exposed mechanisms where dust could accumulate during a lunar mission and degrade the performance or lifetime of the mechanisms, then fewer points will be awarded in this category. If the Lunabot raises a substantial amount of airborne dust or projects it due to its operations, then fewer points will be awarded. Ideally, the Lunabot will operate in a clean manner without dust projection, and all mechanisms and moving parts will be protected from dust intrusion. The Lunabot will not be penalized for airborne dust while dumping into the LunaBin. All decisions by the judges regarding dust tolerance and dust projection are final.

G) During each competition attempt, the team will earn 250 LunaPoints if the Lunabot is able to drive autonomously (no teleoperation), through the obstacle area only. The Lunabot may be teleoperated in the mining area and LunaBin/starting area. A minimum of $10 \mathrm{~kg}$ of BP-1 must be mined and deposited in the LunaBin during each competition attempt to receive these LunaPoints. The points for autonomy through the obstacle area and full autonomy are mutually exclusive.

H) During each competition attempt, the team will earn 500 LunaPoints if full autonomy is achieved and a minimum of $10 \mathrm{~kg}$ of BP-1 is mined and deposited in the LunaBin. No teleoperation is allowed to achieve full autonomy status. The points for autonomy through the obstacle area and full autonomy are mutually exclusive.

It is hoped that these new 2012 rules will result in Lunabot designs that are compatible with the types of requirements that would be used for a Lunar robotic precursor mission. Successful aspects of the university team designs can then be used in commercial activities which will use lunar resources to expand humanity's economic sphere of influence into cis-lunar space and eventually beyond.

\section{LUNABOTICS COMPETITION RESULTS}

In 2010, there were 22 university teams that actually competed at Kennedy Space Center in Florida, USA:

University of Akron

University of Alabama

University of Arkansas

Auburn University 
University of Bridgeport

Carnegie Mellon University, collaborating with Hampton University

Colorado School of Mines

Embry Riddle Aeronautical University - Daytona Campus

Florida Institute of Technology

Florida State University, collaborating with Florida A \& M University

Iowa State University

John Brown University

Milwaukee School of Engineering

Montana State University

University of North Carolina-Charlotte

University of North Dakota School of Engineering \& Mines

Prairie View A \& M University

South Dakota School of Mines and Technology

University of Southern Indiana

Temple University

Virginia Tech

Western Kentucky University

The teams that were awarded prizes are:

Lunabotics Mining in the Lunarena:

1) Montana State University (21.6 Kg)

2) Auburn University ( $<10 \mathrm{Kg}$ )

3) University of Southern Indiana $(<10 \mathrm{Kg})$ 
Systems Engineering Paper: Auburn University

Outreach to Informal Education or K-12 Education: Embry Riddle

Aeronautical University - Daytona Campus

Slide Presentation: Western Kentucky University

Team Spirit Competition: University of Southern Indiana

Joe Kosmo Award for Excellence: Montana State University

First place in the "On-Site Mining" category with a total mass of $21.6 \mathrm{~kg}$, was awarded to Montana MULE from Montana State University - Bozeman. Since there were no other teams that excavated the required minimum of $10 \mathrm{~kg}$, the judges decided to award honorable mentions to the following teams. The $1^{\text {st }}$ and $2^{\text {nd }}$ place honorable mentions received the prize money and VIP launch invitations.

\section{Honorable Mentions:}

$I^{\text {st }}$ place with a total mass of $6.6 \mathrm{~kg}$, was awarded to Team Pumpernickle from Auburn University

$2^{\text {nd }}$ place with a total mass of $2.4 \mathrm{~kg}$, was awarded iDigU from University of Southern Indiana

$3^{\text {rd }}$ place with a total mass of $2.2 \mathrm{~kg}$, was awarded to Moonrockers from South Dakota School of Mines and Technology

$4^{\text {th }}$ place with a total mass of $0.8 \mathrm{~kg}$, was awarded to Luna Baggers from Milwaukee School of Engineering

$5^{\text {th }}$ place with a total mass of $0.6 \mathrm{~kg}$, was awarded to PiRATE from the University of Akron

In 2011, the rules were unchanged except that international participation was allowed. This created a burst of additional interest with 70 teams applying and 60 universities registering and 36 actually competing at Kennedy Space Center. Of these 14 teams were able to excavate regolith and dump it in the collection bin. There were 36 teams from 26 states and 4 foreign countries (India, Bangladesh, Colombia and Canada) represented.

The 2011 Winners by Category were:

The Joe Kosmo Award for Excellence (to the school with the best overall results from all categories): University of North Dakota 


\section{On Site Regolith Mining Award Winners}

1st Place - Laurentian University, Ontario, Canada - 237.4 kilograms

2nd Place - North Dakota University - 172.2 kilograms

3rd Place - West Virginia University - 106.4 kilogram

Judges Innovation Design Award to Embry Riddle Aeronautical University,

Prescott, Arizona Campus

Communications Efficiency Award to Laurentian University

Team Spirit Award - University of Alabama

Team Spirit Honorable Mentions - North Dakota University, Embry Riddle

Daytona Campus \& West Virginia University

Slide Presentation Award - Embry Riddle Daytona

Outreach Project Award - Montana School of Mines

Systems Engineering Paper Award- John Brown University, Arkansas

The 2011 “On-site Mining “ category results were:

1) Laurentian University $237.4 \mathrm{~kg}$

2) University of North Dakota $172.2 \mathrm{~kg}$

3) West Virginia University $106.4 \mathrm{~kg}$

4) Embry Riddle U. - Prescott $\quad 85.4 \mathrm{~kg}$

5) Auburn University $\quad 80.0 \mathrm{~kg}$

6) Virginia Tech $79.0 \mathrm{~kg}$

7) Colorado School of Mines $\quad 72.0 \mathrm{~kg}$

8) University of Alabama $63.2 \mathrm{~kg}$

9) John Brown $50.0 \mathrm{~kg}$

10) Southern Indiana $\quad 37.6 \mathrm{~kg}$

11) South Dakota School of Mines $34.0 \mathrm{~kg}$

12) Temple University $33.6 \mathrm{~kg}$ 


\section{3) University of Akron $32.0 \mathrm{~kg}$}

Other teams were not able to excavate more than $10 \mathrm{~kg}$ of regolith simulant.

\section{LESSONS LEARNED AND DESIGNS}

None of the robots competing in the competitions would be considered space ready hardware. The robots were designed to meet the competition goals and conditions which required the use of only physical principles that would be possible on the lunar surface. Many of the robots would not survive the vibration and loading conditions during launch towards the moon and hence would not be operational when arriving. Some of the robots could be adapted by using space qualified hardware in their design and would be robust enough to survive the launch conditions and space requirements, but those were far and few between. The teams learned a tremendous amount and returning teams showed enormous improvement. Some lessons learned from a participant's perspective can be found in van Susante and Dreyer (2010), (Mueller \& van Susante, 2011).

Regolith Excavation Challenge: 2007. The first competition was a learning experience for everyone including organizers. The observations include that teams were not well prepared because machines were not robust and broke down. This was partially due to not knowing how to operate in JSC-1A which was caused by that simulant not being available (and affordable) for teams to test their robots with. Teams that tested with other substances such as play sand or cement learned that those materials behaved very differently than JSC-1A did. The low power (30 Watt) and required autonomy proved very challenging leading to all designs being stationary designs and using anchoring methods. In addition, many machines were too spindly and structurally unstable which contributed to their failure because most teams under estimated the excavation forces required. (Mueller \& van Susante, 2011).

Regolith Excavation Challenge: 2008. The second competition had many more promising designs but due to a random draw of starting position and orientation all robots had to start in a corner of the competition sand box. This starting position meant there were two walls (one in front and one to the side) and the ramp forming the three sides with the fourth side of the starting square being formed by a rock. The orientation of the robot pointed the front to one of the walls and the rock was to the back of the rover. This made autonomy extremely challenging and only two teams were able to move out of the corner but got stuck before being able to dump any JSC-1A in the box. Many of the structures and systems designed to function as beacons and help the robot orient itself with regards to the box were dubious in quality and robustness. None of the teams managed to dump any regolith. Demo's were run afterwards, mostly telerobotically, and some had good results dumping significant amounts of regolith. Two 
bucket ladders and a bucket wheel performed well during the demo runs. (Mueller \& van Susante, 2011).

Regolith Excavation Challenge: 2009. The third and last Centennial Excavation Challenge was dominated by bucket ladders but also saw some very exotic designs such as one with magnetic wheels designed to pick up the regolith containing iron. First and second place were bucket ladders and the third was a bucket wheel. Most machines in this competition were very tall and had a high center of gravity. All competitors were focusing on gathering maximum amounts of regolith because there were no other judging criteria. Most of the robots generated copious amounts of dust when excavating leading to extremely poor visibility and a breathing hazard for people in the enclosure. One solution was to put brightly colored LED lights on the robot so the position of the robot was still clear despite the poor visibility and contrast. All machines were tele-operated where the operators were isolated visually and auditory from the arena. The built-in time delay caused some teams problem in their control. In addition there were many communication problems because teams had not been able to test with the required use of the provided NASA network. Some teams lost video for instance but could still control their robot. (Mueller \& van Susante, 2011).

Lunabotics Mining Competition: 2010. Only a few university teams (including the 2009 winner) participated in the Centennial Excavation Challenges but the Lunabotics Mining Competition was open ONLY to university teams. That meant a lot of fresh teams who had never participated before. This lead to many mechanical failures (some spectacularly breaking in half or burning out a drive motor with flames coming out of it). Also there were many communication issues and many hours were spent in fixing the operation and compatibility with the required use of the provided secure WiFi NASA network. Many teams were not ready to compete and had no time to test their robots thoroughly. Integration of the subsystems to create a fully functional robot was a challenge and many teams had to work through the night to fix things. Some only got things running for the first time ever just before the competition. The majority of the teams had no access to lunar simulants and thus were surprised by the behavior of it in the box when trying to excavate it. This included the natural presence of small rocks that caused some systems to jam. (Mueller \& van Susante, 2011).

Lunabotics Mining Competition: 2011. The second Lunabotics competition showed a very strong field of teams with many now being veterans. 70 teams applied, 60 teams registered, and 36 made it to the Kennedy Space Center Visitor Complex. Out of the 36 teams, 14 managed to deposit BP-1 simulant in the collection bin. All teams showed great improvement from 2010. This year was the first year that international participation was possible. The international teams provided some very innovative ideas but some showed great similarity with the big spindly designs of earlier competitions. Due to the travel requirements they had to design their robot to fit in several suitcases which also meant that a lot of their time was spent in putting the robots together instead of testing. The level of the competition was much higher than in 
2010 which can be seen from the fact that the 2010 winner would be placed $14^{\text {th }}$ in 2011. One of the important facts is that transfer of lessons learned from one year to the next greatly improves next years' teams performance. (Mueller \& van Susante, 2011).

\section{GOOD PRACTICES FOR LUNABOTICS MINING ROBOT DESIGN.}

One of the goals of the Lunabotics competition is to create designs and prototypes of Lunabot excavation machines that could plausibly function on the moon if developed further with space qualified components and other enhancements such as thermal control systems. Since the first step in deploying to the moon is to launch on a rocket which experiences up to $5 \mathrm{G}$ 's of acceleration vertically, these lunabots must be compact and strong enough to withstand the launch loads and constrained shroud volume. Then the lunabot must deploy to the lunar surface and unpackage itself, leading to further challenges. At this point the lunabot can start mining regolith and delivering it to the lunar end user. To successfully execute these critical events, good design and operations practices must be used. The alternative is to have a mission fail at a great cost and embarrassment. (Mueller \& van Susante, 2011)

Lunabot Inspections. All Lunabots will be inspected to ensure safe operations and compliance with the rules. An emergency stop button must be present so that judges can disable the lunabot in the event of a fire or other mis-hap.

The mass and stowed dimensions will also be verified. A communications check will be performed to ensure that the rules are being met and that there is no radio frequency interference with other communications systems in the area. All teams are advised to be prepared for these checks by doing an internal audit before arriving at the competition. This will expedite the inspections and will avoid unnecessary disqualification.

Regolith Simulants \& Mining. The regolith simulant used in Lunabotics is a geotechnical bulk simulant that has a particle size distribution very similar to actual lunar regolith as measured from Apollo Mare samples, and it is made of crushed basalt from the Black Point lava flow in Arizona which is very similar to the lunar mare mineralogy. Black Point-1 (BP-1)_- A crushed lava aggregate with a natural particle size distribution similar to that of lunar soil. The aggregate will have a particle size and distribution similar to the lunar regolith as stated in the Lunar Sourcebook: A User's Guide to the Moon, edited by G. H. Heiken, D. T. Vaniman, and B. M. French, copyright 1991, Cambridge University Press. Teams are encouraged to develop or procure simulants based on lunar type of minerals and lunar regolith particle size, shape, and distribution.

Many teams have used sand and other commonly available granular materials only to find that the cohesive behavior of BP-1 is completely different when compacted to the correct bulk density as found on the moon. Teams are advised to use granular materials that are cohesive, or can be compacted or altered ( e.g. wet sand) to make it more cohesive. 
Wireless Communications Bandwidth. Space Exploration does not always afford a high bandwidth capability- so the lunabot should attempt to minimize the bandwidth used at all times. Using sub- routines that reside on board may mitigate high communications rates and using just the house camera is another way to reduce communications data rate needs.

All communications devices should be thoroughly tested at the University prior to competing, since previous competitions indicate that this is an area which has high potential for creating problems for the lunabot operation.

Lunabot Mass. Since launch costs vary between $\$ 4,000$ to $\$ 10,000$ per pound to Low Earth Orbit, and more to transport it to the Moon (as high as $\$ 100,000$ per pound) it is highly desirable to minimize the mass of the Lunabot. This creates difficulties since a low mass in $1 / 6$ th $\mathrm{G}$ means that there will be a very low reaction force to counteract the digging forces. This means that ingenuity and clever design will have to be employed to keep the lunabot both light and effective for excavation. Innovative uses of lightweight materials, efficient structural design and packaging will help to minimize mass.

Energy Consumed by the Lunabot. Since energy must be stored on board the robot, the mass and complexity of the energy storage device will drastically affect the lunabot mass and operations ability. If batteries are used then capacity and re-charging time will play a major role in the capability of the lunabot. For this reason it is required to minimize the energy consumed by the lunabot. Each team is asked to devise a way to measure the energy consumed by the lunabot during the competition run, so that awareness of this critical variable will be a part of the lunabot design and operation.

Dust Tolerant Design and Minimum Dust During Operations. Many lunar excavation robot designs have been generated and built in the last five years for the sole purpose of winning a competition based on maximizing regolith excavated in a set time period. However, on the moon, many of these machines would break down after a short period of operating time, because the sharp, electrostatically charged, abrasive dust will intrude and clog mechanisms and moving parts if they are exposed and not sealed. In order to be most lunar like all teams should strive to protect all mechanisms, joints, sensors and other vulnerable sub systems from dust intrusion and damage.

Autonomy while Driving through the Obstacle Area. Autonomy is difficult and relies on sophisticated sensor perception systems and on board real time data processing. A partial level of autonomy is an option, where the lunabot can be made semi-autonomous. In this mode it just navigates the obstacle area autonomously and the rest of the time it is tele-operated.

Fully Autonomous Lunabot. A fully autonomous robot will be very useful for areas and planets where line of sight communications or communications delays make it 
impossible to directly tele-operate the robot. If a lunabot has full autonomy, then this demonstrates a mastery of robotics technology and will be highly rewarded in the competition. No tele-operation is allowed in this mode, and it is highly advised to do extensive check out testing prior to the competition. A tele-operated back-up mode is also a good way to recover from potential failures during the competition.

\section{SUMMARY}

The NASA Lunabotics Mining competition has been a successful spin off from the NASA Centennial Challenges Regolith Excavation Challenge. It has been held for two years with growing interest in each year. In 2010, 22 United States (US) universities competed, and in May 2011 the competition was opened to international participation. In 2011, 36 teams actually competed from 26 USA states and 4 foreign countries (India, Bangladesh, Colombia and Canada). 70 teams applied, 60 registered, 44 submitted a Systems Engineering paper. By the time registration was closed for the third annual 2012 competition, over 80 universities had applied for admission, with 72 universities accepted.

Historically there has been a $50 \%$ attrition rate - so every team that actually came to $\mathrm{KSC}$ is to be commended. The team that placed $13^{\text {th }}$ in 2011 would have won the competition in 2010, so substantial progress is being made in Lunabot performance. The winning team mined an equivalent of about 1 metric ton per hour of regolith.

The NASA Constellation program ISRU requirement to make 10 metric tons of $\mathrm{O} 2$ required about 1,000 metric tons of regolith per year and a lunabot could meet this requirement in about 8 months if only operating with one 8 hour shift per Earth day. However, none of the machines would have survived the lunar environment or lifetime as designed, even if space qualified hardware were used in the opinion of the judging team.

The cost of the Lunabots ranged from $\$ 5,000$ to $\$ 25,000$ and the team sizes ranged from 2 to 17 members, with an average of about 10 members from multiple disciplines. Two semesters were spent designing and building for college credit.

The enthusiasm and degree of expertise displayed by all of the students was impressive and NASA management is highly supportive of the Lunabotics Mining Competition due to the positive effect it has had on the students involved. Our sponsors have also been impressed and are continuing their support. Caterpillar has hired three of the Lunabotics students for full time jobs and student resumes are made available to all sponsors for hiring consideration.

We hope that in the future these students will be involved in the space industry or at a minimum that they will support it as future leaders, taxpayers and voters. 


\section{REFERENCES}

[1]Davidian, K. (2005), "Prize Competitions and NASA's Centennial Challenges Program", International Lunar Conference, 2005

[2] Everingham, Matthew R., Pelster, Nicholas, Mueller, Robert P., Davidian, Kenneth (2008). "Preparation and Handling Large Quantities of JSC-1A Lunar Regolith Simulant for the 2007 Regolith Excavation Challenge", STAIF 2008, Albuquerque, New Mexico.

[3] King, R. H., Duke, M. B. and Johnson, L., "Evaluation of Lunar-Regolith Excavator Concepts for a Small, ISRU Oxygen Plant," (2005), www.lpi.usra.edu/meetings/leag2005/presentations/wed_am/06_king.pdf, October 3, 2007.

[4] Mueller, Robert P. and Robert H. King, "Criteria for Lunar Outpost Excavation," Proceedings of Space Resources Roundtable IX, Colorado School of Mines, CO, 2007.

[5] Mueller, Robert P. and van Susante, Paul J., "A Review of Lunar Regolith Excavation Robotic Device Prototypes", AIAA Space 2011 Conference, Long Beach, California, USA

[6] Santa Maria Times newspaper article, May 2007

[7] Steidle, Craig E. (2004), NASA Administrator Presentation to the Subcommittee on Space and Aeronautics Committee on Science United States House of Representatives

[8] van Susante, P.J. and Dreyer, C.B. (2010). "Lunar and Planetary Excavation Prototype Development and Testing at the Colorado School of Mines", Earth and Space 2010, Engineering, Science, Construction, and Operations in Challenging Environments, Edited by Gangbing Song, Ph.D.; Ramesh B. Malla, Ph.D., ASCE 


\section{Lunabotics Mining Competition: Inspiration through Accomplishment}

ASCE Earth \& Space

Pasadena, California

April 18, 2012

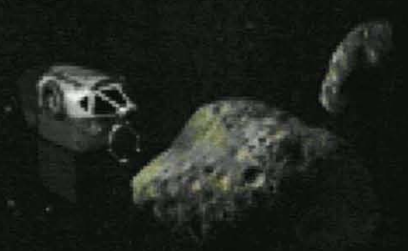

Rob Mueller,

Senior Technologist, Surface Systems Office NASA Kennedy Space Center, (KSC) Florida 


\section{Introduction: Leveraged Prizes}

In 2005 the United States of America congress funded a program of contests to stimulate innovation and competition in technical areas of interest to NASA.

- This program consists of the NASA Centennial Challenges, a collection of public contests designed to stimulate technological innovation in areas that benefit space exploration. The intent was to build on historic and current prize experience.

As early as the 18th century, the British government offered the Longitude Prize, a competition for a navigational solution to the accurate determination of longitude on the high seas. At the time the prize was set, it was assumed that the solution laid in using star maps as navigational aides and that the winner would be an astronomer. The solution was actually achieved by a London clockmaker and his invention, the marine chronometer [Steidel, 2004].

- Another historic prize was the $\$ 25,000$ Orteig Prize which was offered in 1919 by a prominent New York businessman, Raymond Orteig, for the first non-stop flight from New York to Paris. It was won in May, 1927 by Charles Lindbergh and is widely credited with stimulating public interest in commercial passenger flights and bolstered confidence in airplane safety.

More recently the Ansari X PRIZE was a space competition in which the X PRIZE Foundation offered a US\$10,000,000 prize for the first non-government organization to launch a reusable manned spacecraft into space twice within two weeks. $\$ 10$ million was awarded to the winner, but more than $\$ 100$ million was invested in new technologies in pursuit of the prize. 
- The first NASA competition related to excavating lunar regolith simulant was organized by the California Space Education and Workforce Institute (CSEWI) and the California Space Authority (CSA) as partner organizations to NASA (Everingham, 2008). This event was held in Santa Maria, California from May 11-12, 2007, with a prize of $\$ 250,000$ offered to the competitor that excavated the most simulated lunar regolith and deposited it in a collection box.

- The lunar regolith simulant used was 8 tons of JSC-1a, which is widely used for NASA lunar research activities. In this challenge, teams designed and built robotic machines to excavate simulated lunar soil (regolith).

- Excavating regolith will be an important part of any construction projects or processing of natural resources on the Moon (Mueller, 2007). The robots were tested in a box containing eight tons of simulated lunar regolith that is about 4 meters square and about one-half meter deep.

- The teams with the robots that moved the most regolith could claim the three cash prizes. NASA is looking for new ideas for excavation techniques that do not require excessively heavy machines or large amounts of power.

- The competition required autonomous robots with a simulated wireless signal time delay of several seconds simulating lunar communications. There were four teams of engineers competing to be the first to build a robot capable of collecting at least 150 $\mathbf{k g}$ of lunar soil in less than $\mathbf{3 0}$ minutes. Machines also could use only $\mathbf{3 0}$ watts of power , which was provided by a "house" tether and had to weigh less than $40 \mathrm{~kg}$ as they excavated the simulated lunar regolith defeated the competitors. 
The teams that actually competed were:

Technology Ranch, Pismo Beach - 65.25 kg

- The Lunar Miners, University of Missouri-Rolla -Broke down while digging.

$\checkmark$ Duplex Engineering, Michigan, Geoffrey Pulk - Broke down while digging.

- Todd Mendenhall, Mendenhall BFD excavator - Broke down while digging

\section{No Prize was awarded in 2007}


The 2008 Regolith Excavation Challenge was held on Aug. 2 and 3 on the campus of the California Polytechnic State University in San Luis Obispo, CA.

The 2008 prize purse was $\$ 750,000$, and the rules were not changed significantly from 2007, but mass allowed was increased to $70 \mathrm{~kg}$ and the available tethered power was increased to 150 watts.

- In addition a 20 degree inclination (from horizontal) ramp was provided to all the teams.

- Twenty-five teams registered for the competition. Sixteen teams came to San Luis Obispo, at the Cal Poly Campus, to compete and although no team was able to win the prize, the competition was very spirited.

- To autonomously navigate through randomly placed rocks and to reach a collection box at the top of a ramp proved to be a taxing technical challenge for all of the entrants. The task required expert integration of multiple systems and thorough testing of complex operational scenarios. 
In total 25 teams registered for the event, but only 16 traveled to the Central Coast. Half of those ended up dropping out due to mechanical or logistical problems.

The final teams to compete were:

Waldbaum, Sunnyvale, CA

Next Step, Houston, TX

- Tech Ranch, Arroyo Grande, CA

LuneOreDiggers, Denver, CO

- Cal Poly Slobotics, San Luis Obispo, CA

Team of One, Detroit, MI

- Toy Garden, Friday Harbor, WA

Boppers, Huntington Beach, CA

None of the teams were able to autonomously excavate and deliver any regolith - No Prize was Awarded in 2008 
Twenty-three teams registered for the challenge and traveled from across the country to compete. Of the 23 teams, only 19 competed, one was disqualified as a result of specification violations and the rest withdrew on their own due to last-minute mechanical or logistical problems.

- Teams were allowed to tele-operate their robots instead of requiring them to be fully autonomous as in previous years.

- The team's drivers were isolated in a room separate from the robot and field and had to control their robot through a competition-provided twosecond delay on the sending and receiving of commands.

- Teams were limited to 1000 kbs communication bandwidth averaged over their 30-minute run.

- Competitors were required to provide their own onboard power. To account for the onboard power requirement, the weight limit was increased from $70 \mathrm{~kg}$ to $80 \mathrm{~kg}$. 
These teams pushed their robotic competitors to the limit and three teams claimed a total of $\$ 750,000$ in NASA prizes

First Place: Paul's Robotics, Worcester, MA 437 Kg Regolith (\$500 K)

Second Place Terra Engineering, Gardena, CA 270 Kg Regolith (\$150 K)

Third Place: Team Braundo, Rancho Palos Verde, CA $263 \mathrm{Kg}$ Regolith (\$100 K)

Special mention was given to Team E-REX and Eric Jones of Little Rock, AR for transferring the most regolith, $75 \mathrm{~kg}$, in a single deposit of simulated lunar substance into the official collector bin.

- Competitors were required to use mobile, robotic digging machines capable of excavating up to at least $150 \mathrm{~kg}$ of regolith and depositing it into a container in 30 minutes or less. 
Annual NASA Lunabotics Mining Competition A Centennial Challenges Spinoff for University Teams

Held Annually since 2010

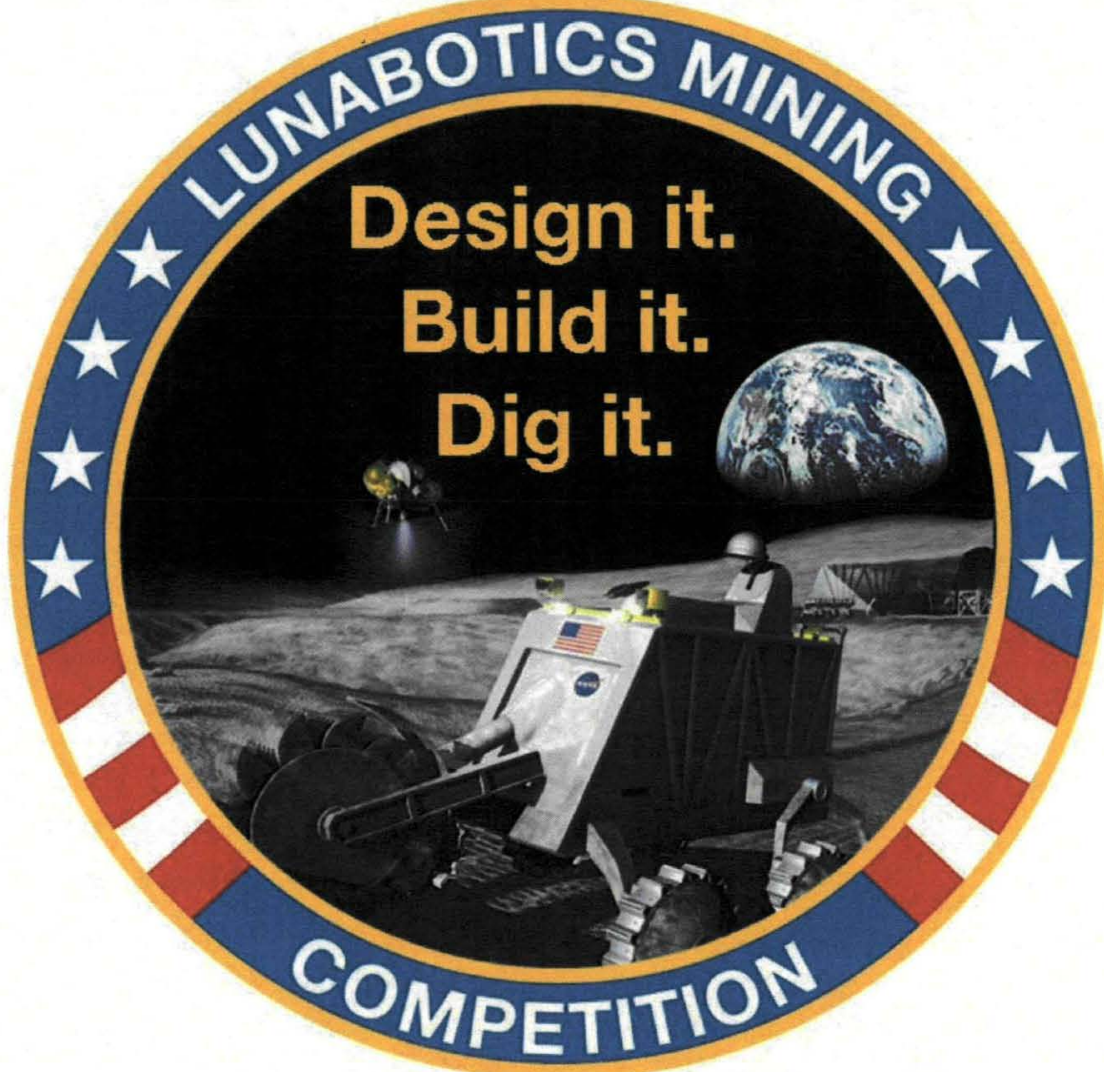

Show Video 
$\checkmark$ Robot Controlled Remotely or Autonomously

$\checkmark$ Visual and Auditory Isolation from Operator

Excavates Black Point 1 (BP-1) Simulant

Weight Limit - $80 \mathrm{~kg}$

$\checkmark$ Dimension Limits $-1.5 \mathrm{~m}$ width $\times \mathbf{. 7 5 m}$ length $x .75 \mathrm{~m}$ height

Designed, Built and Tested by University Student Teams
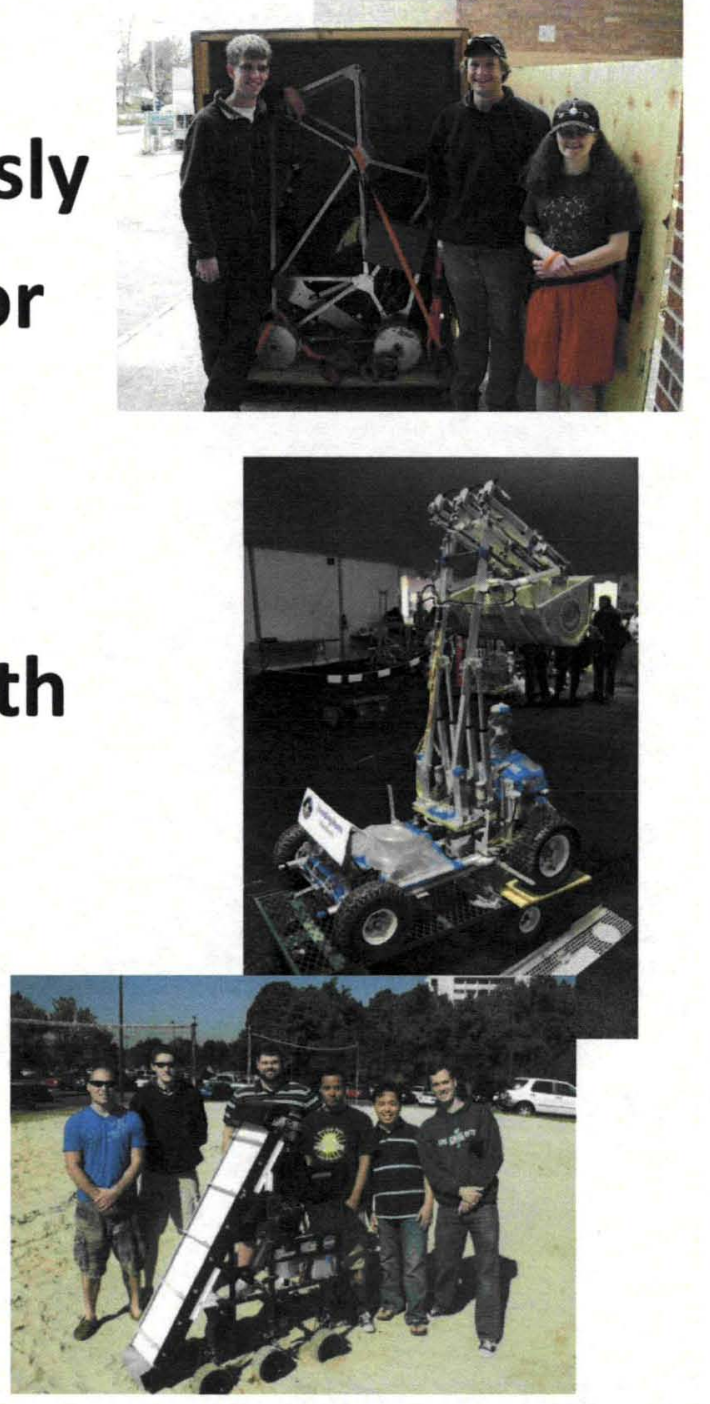


\section{LunArena}

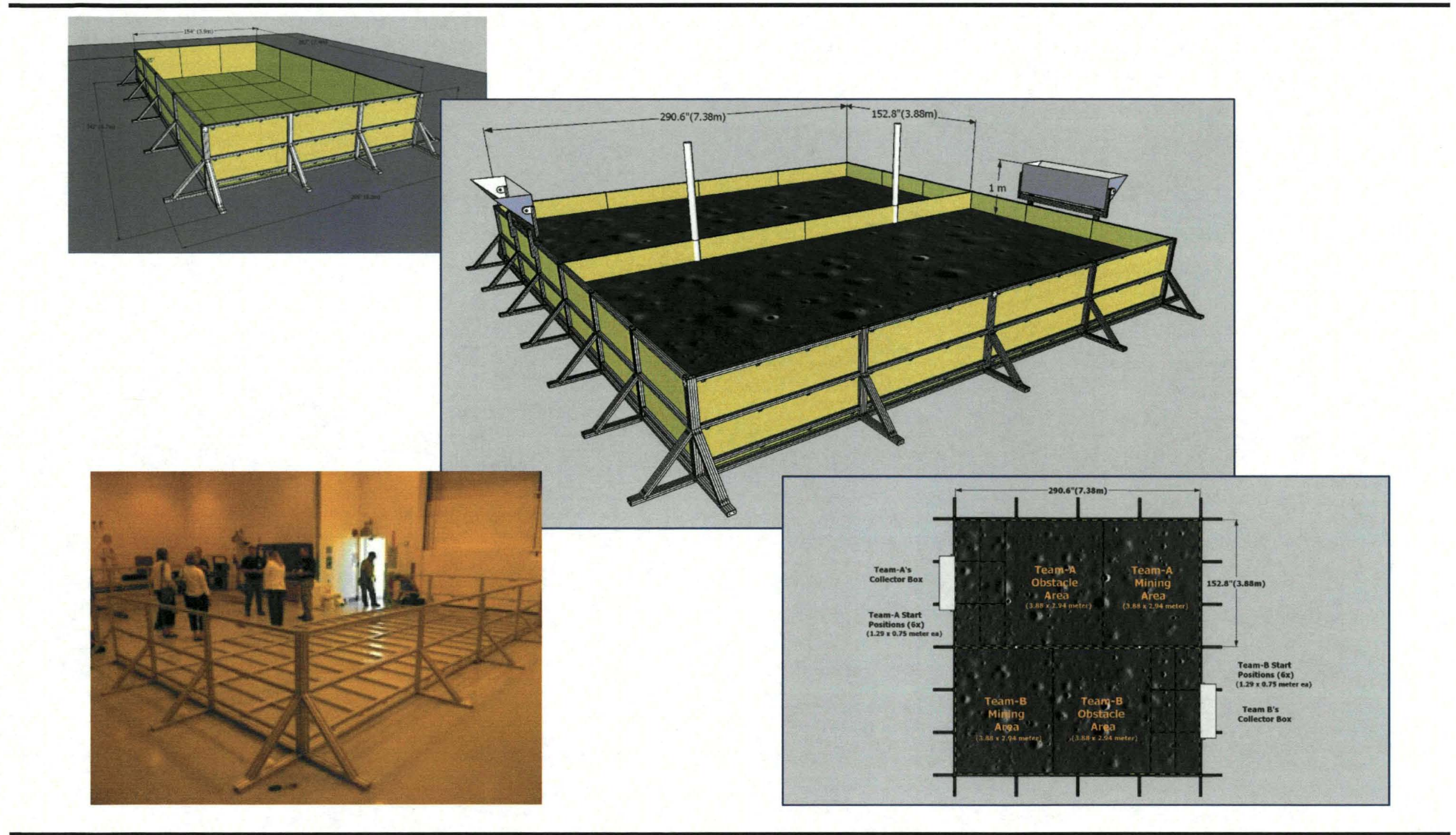




\section{Black Point 1 (BP-1) Lunar Regolith Simulant}

Discovered during 2009 Desert RATS field testing near Flagstaff, AZ

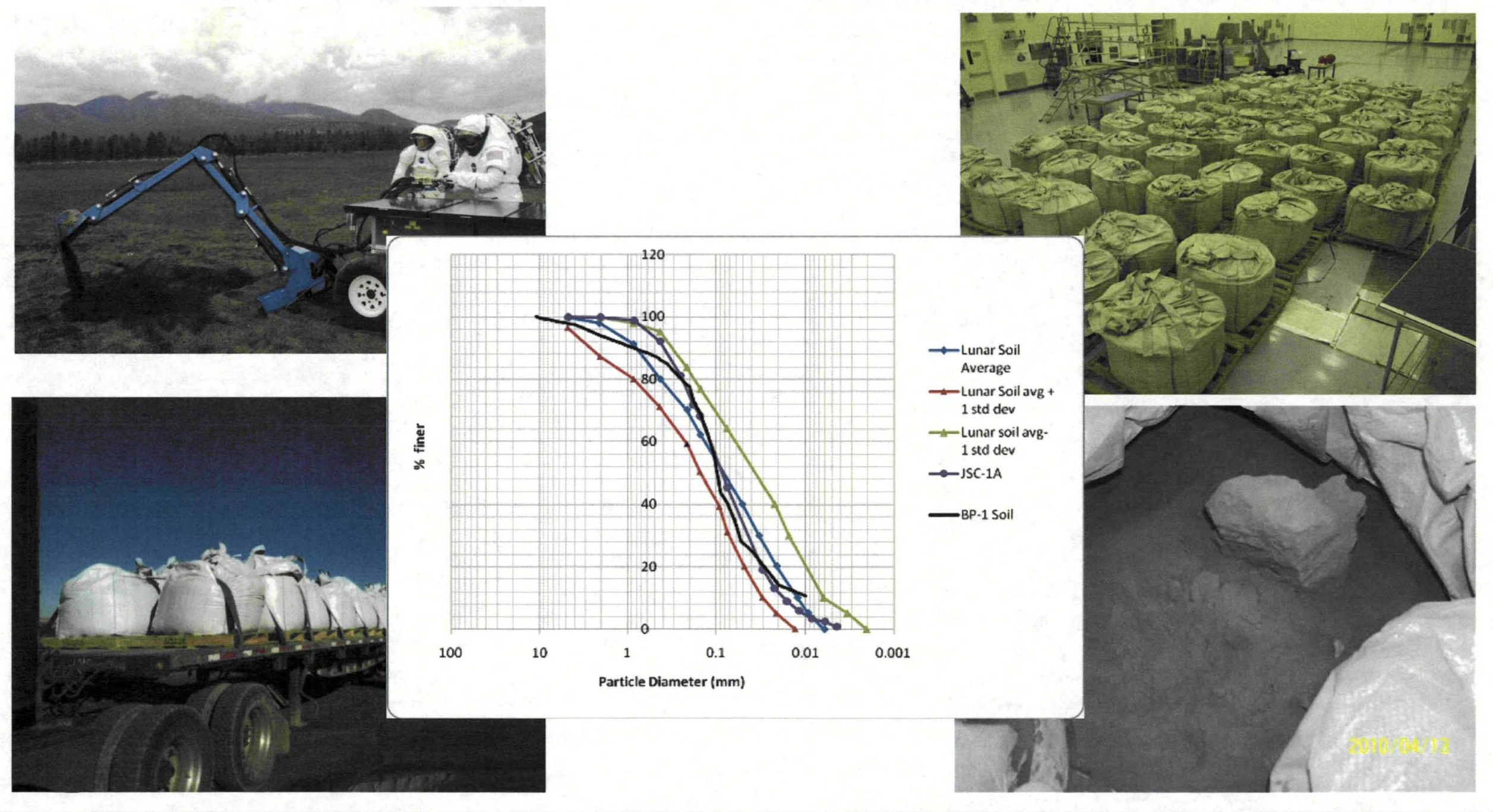




\section{Overview}

- Design, build \& compete remote controlled robot (Lunabot)

- Excavate Black Point 1 (BP-1) Lunar Simulant

- Deposit minimum of $10 \mathrm{~kg}$ of BP-1 within 10 minutes - 2 Competition Attempts Allowed

- \$5000, \$2500, \$1000 Scholarships for most points scored in several judging criteria

- Held Annually May 23-28

- Located at Kennedy Space Center, FL Visitor's Center

- International Teams Invited 
- The Lunabotics Mining Competition is a university-level competition designed to engage and retain students in science, technology, engineering and mathematics (STEM).

- NASA will directly benefit from the competition by encouraging the development of innovative lunar excavation concepts from universities which may result in clever ideas and solutions which could be applied to an actual lunar excavation device or payload.

- Prepare Students for Future Workforce

$\checkmark$ 25' x 25' Regolith Bin for New Technologies Development

- Trigger New Concepts for Regolith Excavation Technologies

- Community Awareness of Future KSC Activities

Outreach to local middle schools, FIRST Robotics, Girl Scouts and Boys \& Girls Club

- KSC Visitor Center Tourist Attraction and Educational Event 
On-site Mining

- $1^{\text {st }}, 2^{\text {nd }} \& 3^{\text {rd }}$ Place for most lunar simulant deposited in collector within 15 minutes

- Minimum of $10 \mathrm{~kg}$ required to place

Systems Engineering Paper (mandatory)

Outreach Project (mandatory)

Slide Presentation (optional)

Team Spirit (optional)

$\checkmark$ Joe Kosmo Award for Excellence 


\section{Systems Engineering Senior Design Capstone Project}

http://education.ksc.nasa.gov/esmdspacegrant/LunarRegolithExcavatorCourse/index.htm

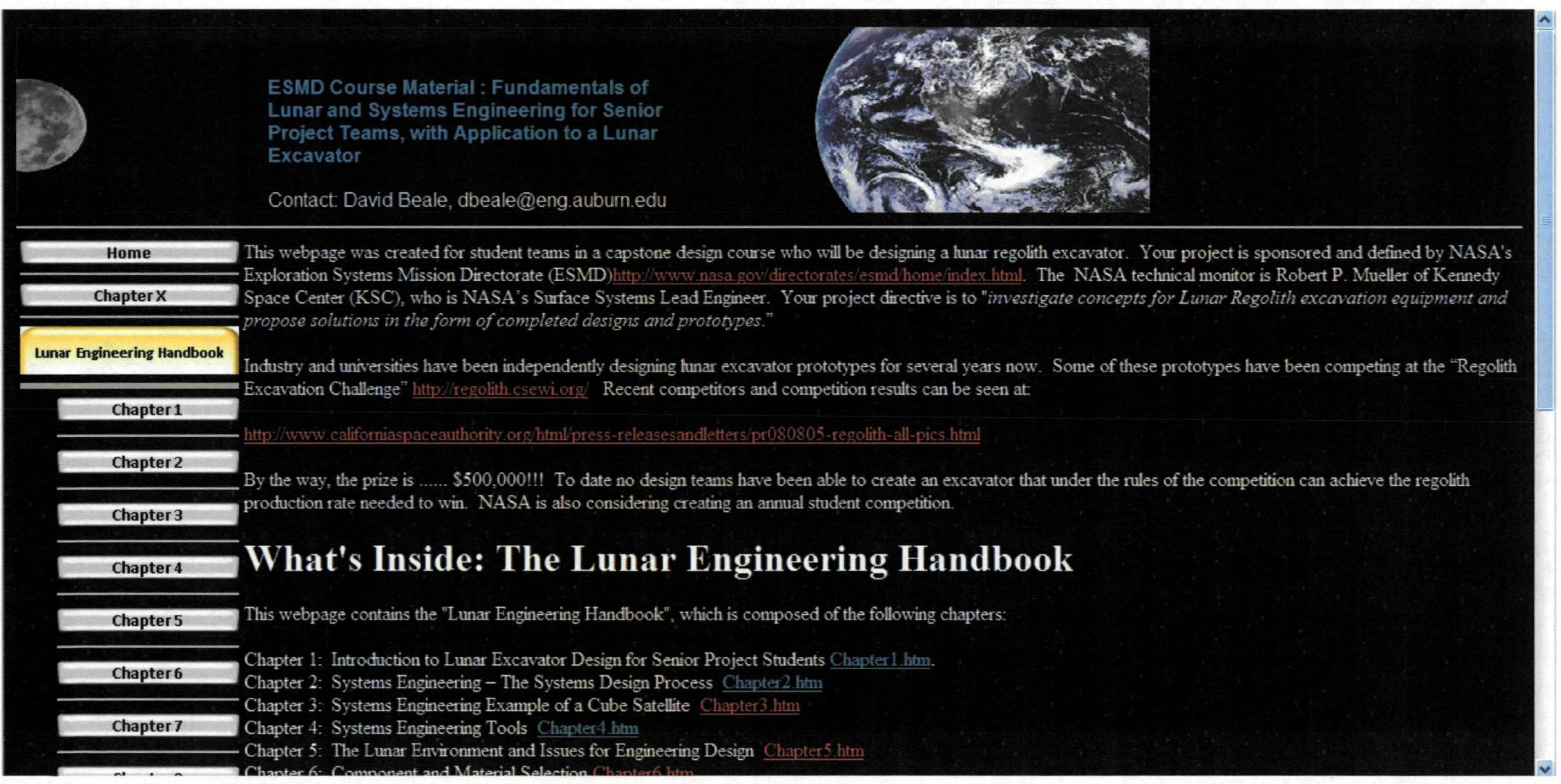




\section{Lunabotics 2011: \\ 44 Lunabotics Teams / 72 Registered 36 Competed at KSC}

ALEX

Auburn University

LunarTechs

California State University, Sacramento

Collaborating with Modesto Junior

College

Mile High Miners

Colorado School of Mines

LAR-E (Lunar All-terrain Regolith

Excavator)

Embry Riddle Aeronautical University,

Prescott

Moon Pi

Embry-Riddle Aeronautical University,

Daytona

The HEXCAVATOR Project

Florida State University

Cheese Graters

Harvard University

ISU Lunabotics - Team LunaCY

lowa State University

Henderson Moon Shredders

ITT Technical Institute Henderson, NV

Golden Eagles

John Brown University

Munabotics

Marquette University

R\&T Robotics Team

Middle Tennessee State University

Collaborating with Tennessee State

University
Manatee Mining Syste

Milwaukee School of Engineering

Montana MULE 2.0

Montana State University

Montana School of Mines

Montana Tech at University of Montana

Aggies Lunabotics Team

New Mexico State University

HOPE

Oakton Community College

NYU-Poly Atlas

Polytechnic Institute of New York University

SDSM\&T Moonrockers

South Dakota School of Mines and Technology

Lunar Solutions

Temple University

Texas A\&M University at Prairie View

Texas A\&M University at Prairie View

Dust Devil

The University of Akron

Collaborating with Elon University

Alabama Lunabotics

University of Alabama

Space Hogs

University of Arkansas - Fayetteville 


\section{Lunabotics 2011: More University Teams}

NMIMS-UH Space Miners

University Of Houston

Collaborating with NMIMS, India

Illinois Robotics In Space (IRIS)

University of Illinois at Urbana-Champaign

LunaCats

University of New Hampshire

49er Luna Miners

University of North Carolina in Charlotte

Raptor

University of North Dakota

University of Portland Robotics

University of Portland

Lunar Ash Borers

University of Southern Indiana

Virginia Tech

Virginia Polytechnic Institute and State
Mountaineers

West Virginia University

A.R.T.E.M.I.S.

Western Kentucky University 


\section{Lunabotics 2011: International University Teams}

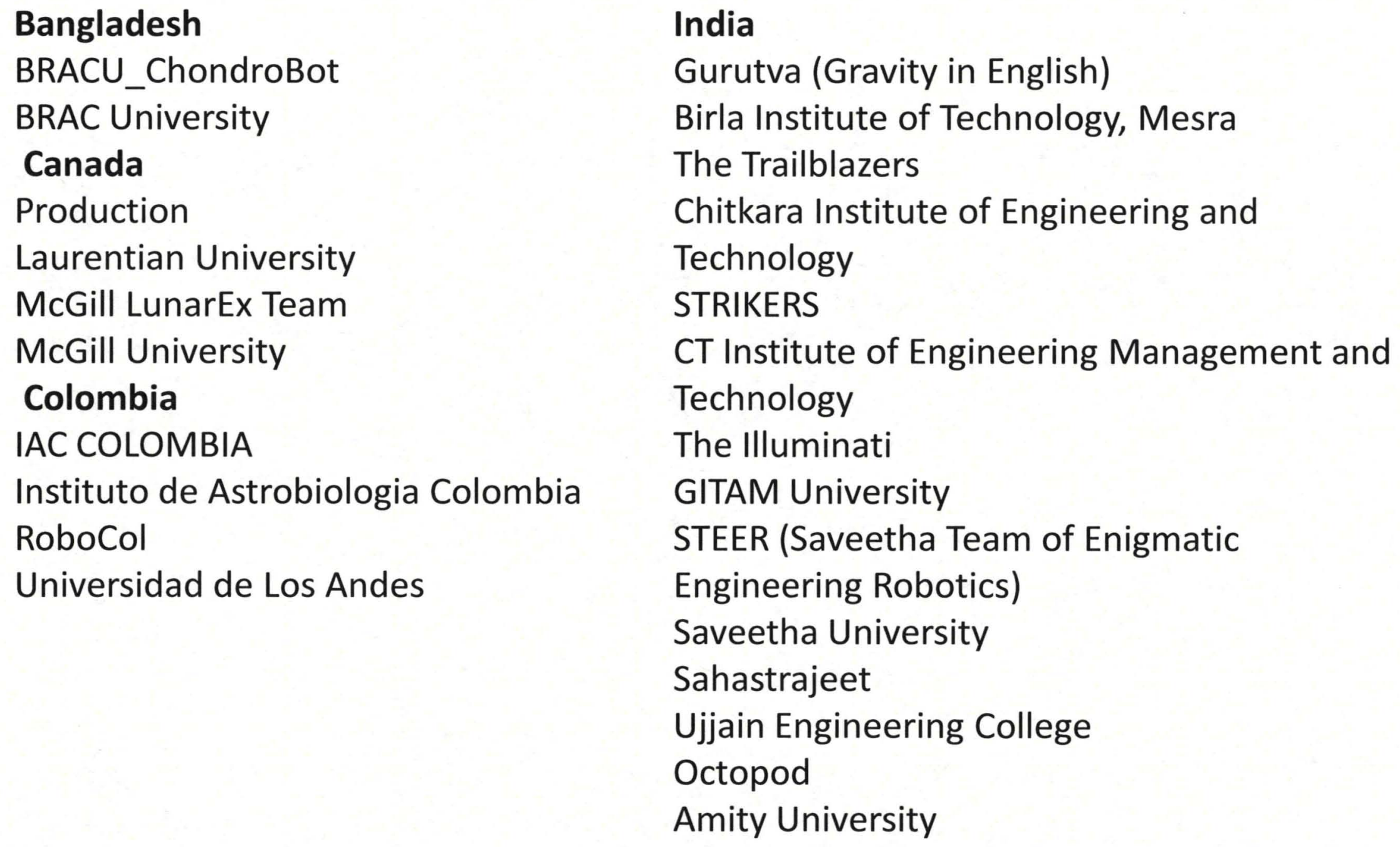

India

Gurutva (Gravity in English)

Birla Institute of Technology, Mesra

The Trailblazers

Chitkara Institute of Engineering and

Technology

STRIKERS

CT Institute of Engineering Management and Technology

The Illuminati

GITAM University

STEER (Saveetha Team of Enigmatic

Engineering Robotics)

Saveetha University

Sahastrajeet

Ujjain Engineering College

Octopod

Amity University 


\section{The Competition}

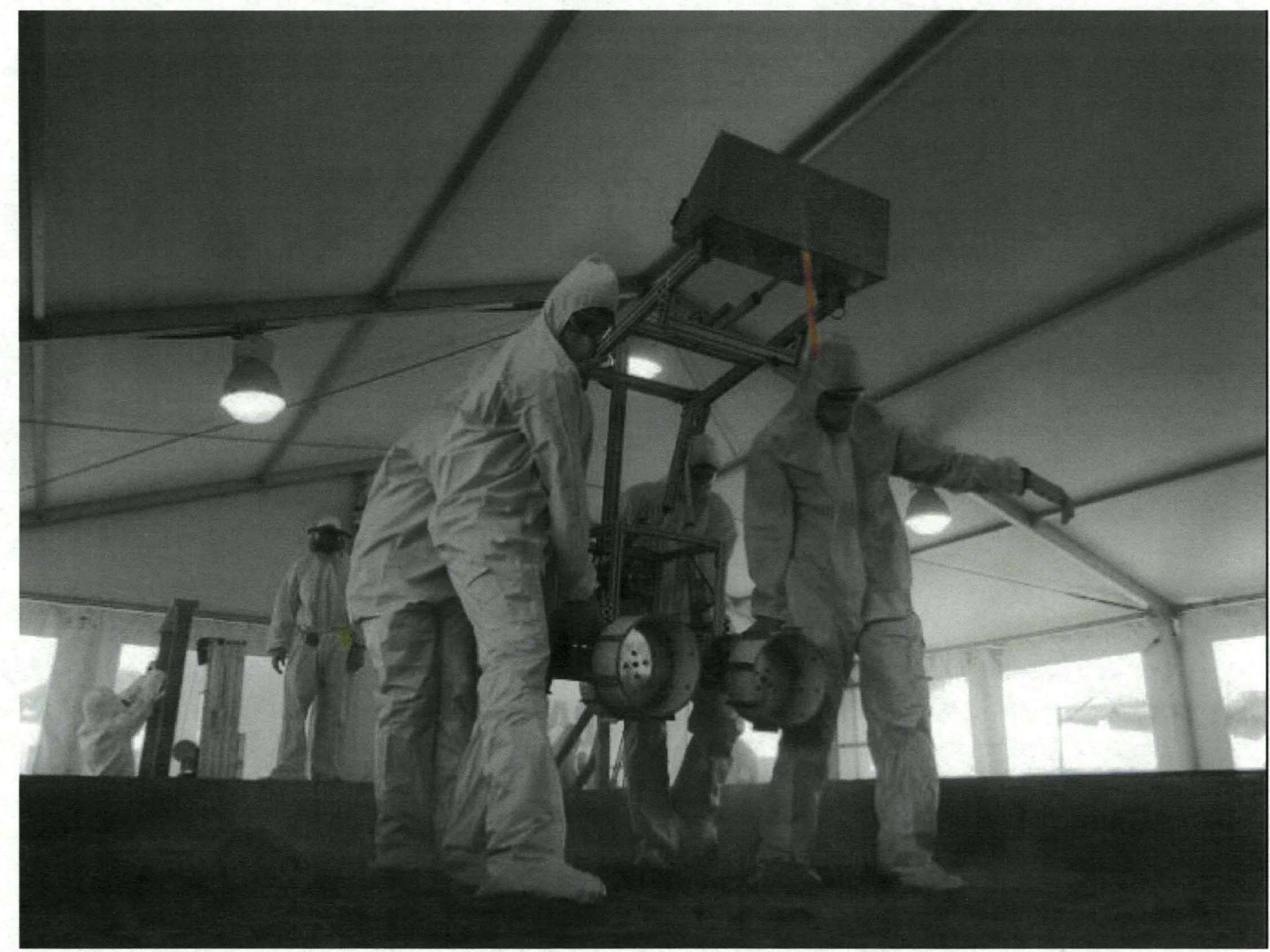


Team Spirit in abundance!

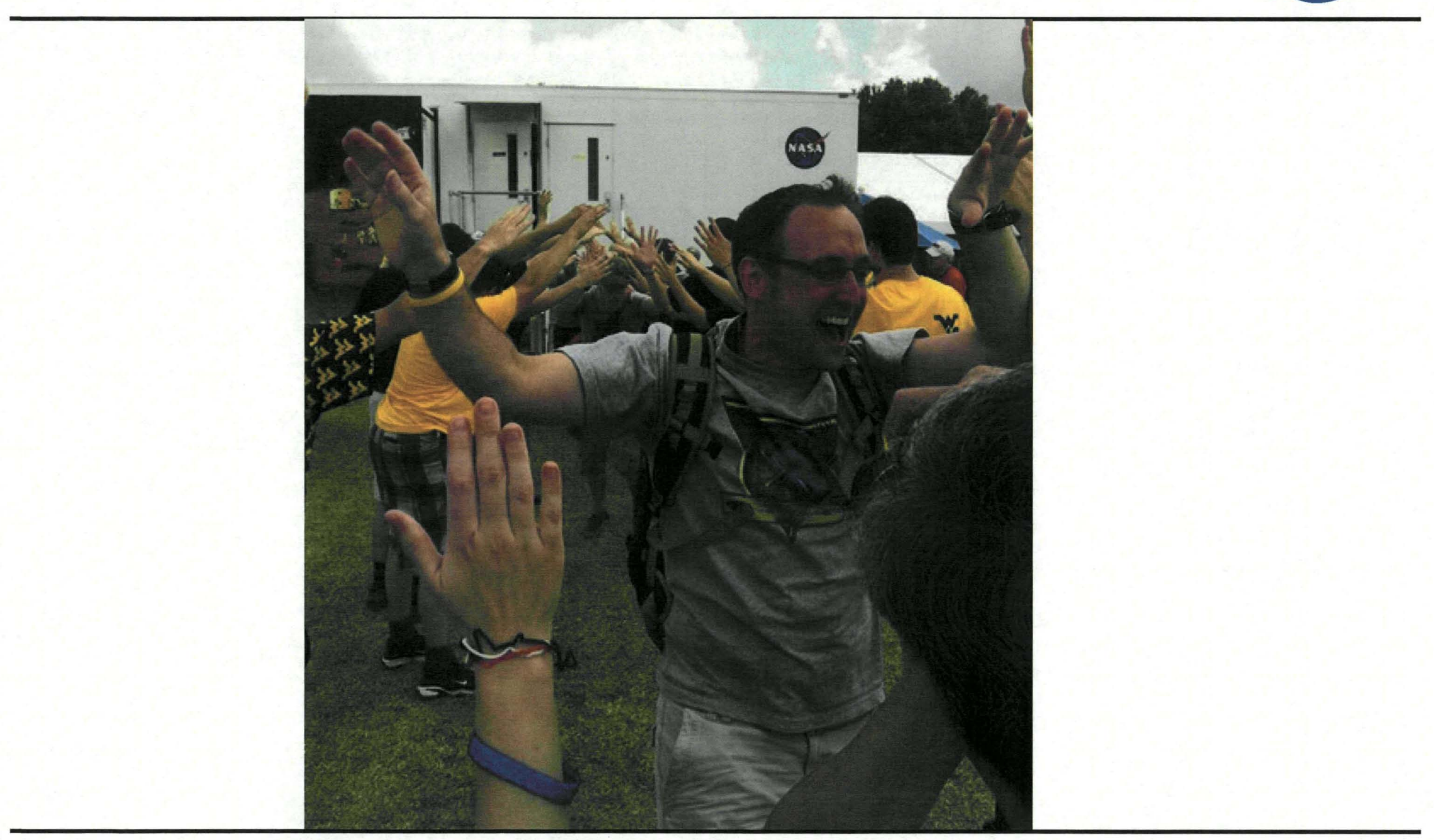




\section{Jumbotron Scoreboard}

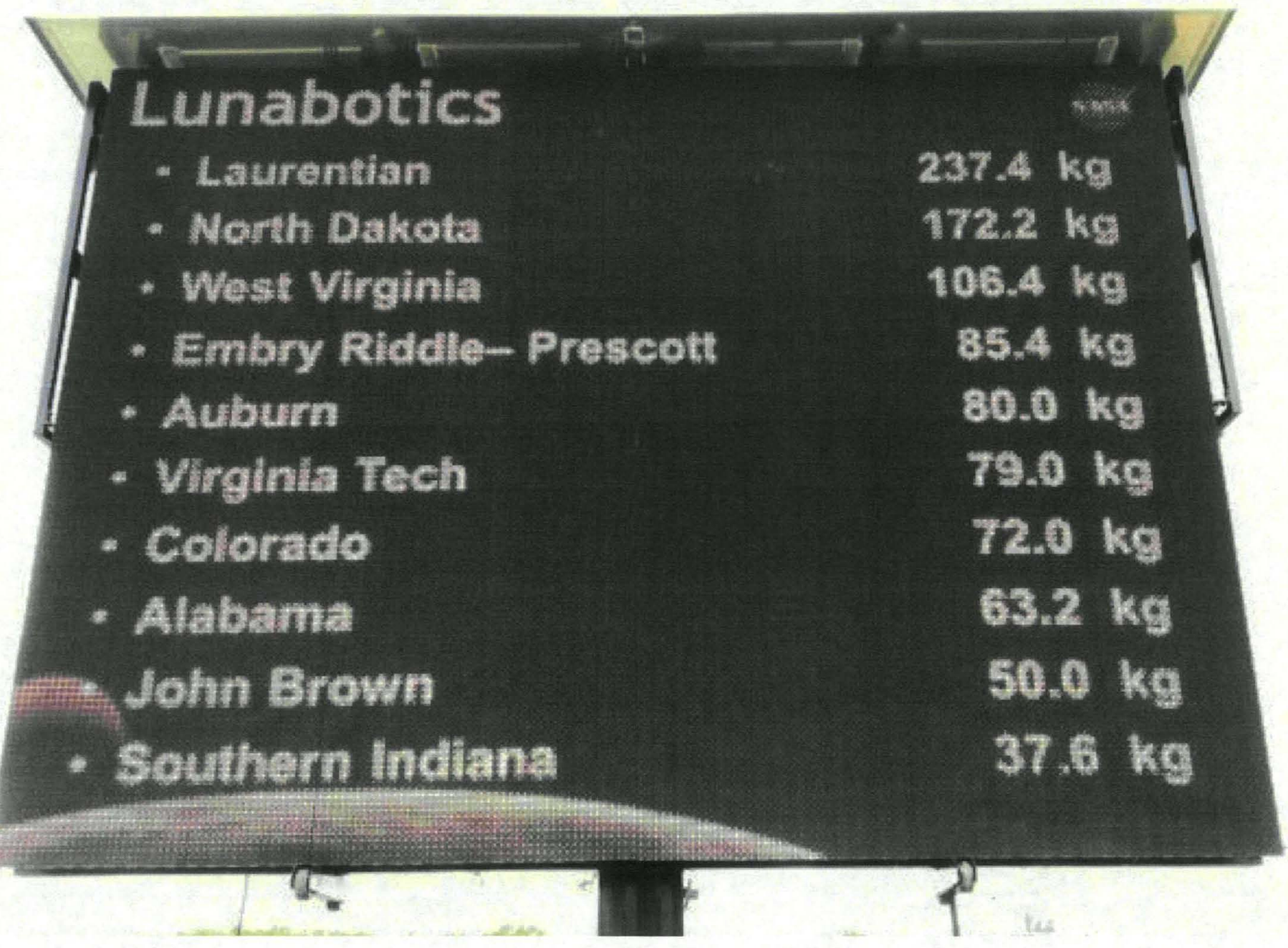




\section{Lunabotics 2011: Regolith Mining Scores (Kg)}

1) Laurentian University - 237.4 On-Site Mining Winner

2) Univ. of North Dakota - 172.2 Joe Kosmo Award Winner

3) West Virginia University - 106.4

4) Embry Riddle University - Prescott - 85.4 Innovation Award Winner

5) Auburn University- 80.0 Team Spirit Winner

6) Virginia Tech - 79.0

7) Colorado School of Mines - 72.0

8) University of Alabama - 63.2

9) John Brown University - 50.0 Systems Engineering Paper Winner

10) Southern Indiana University - 37.6

11) South Dakota School of Mines - 34.0

12) Temple University - 33.6

13) University of Akron - 32.0 


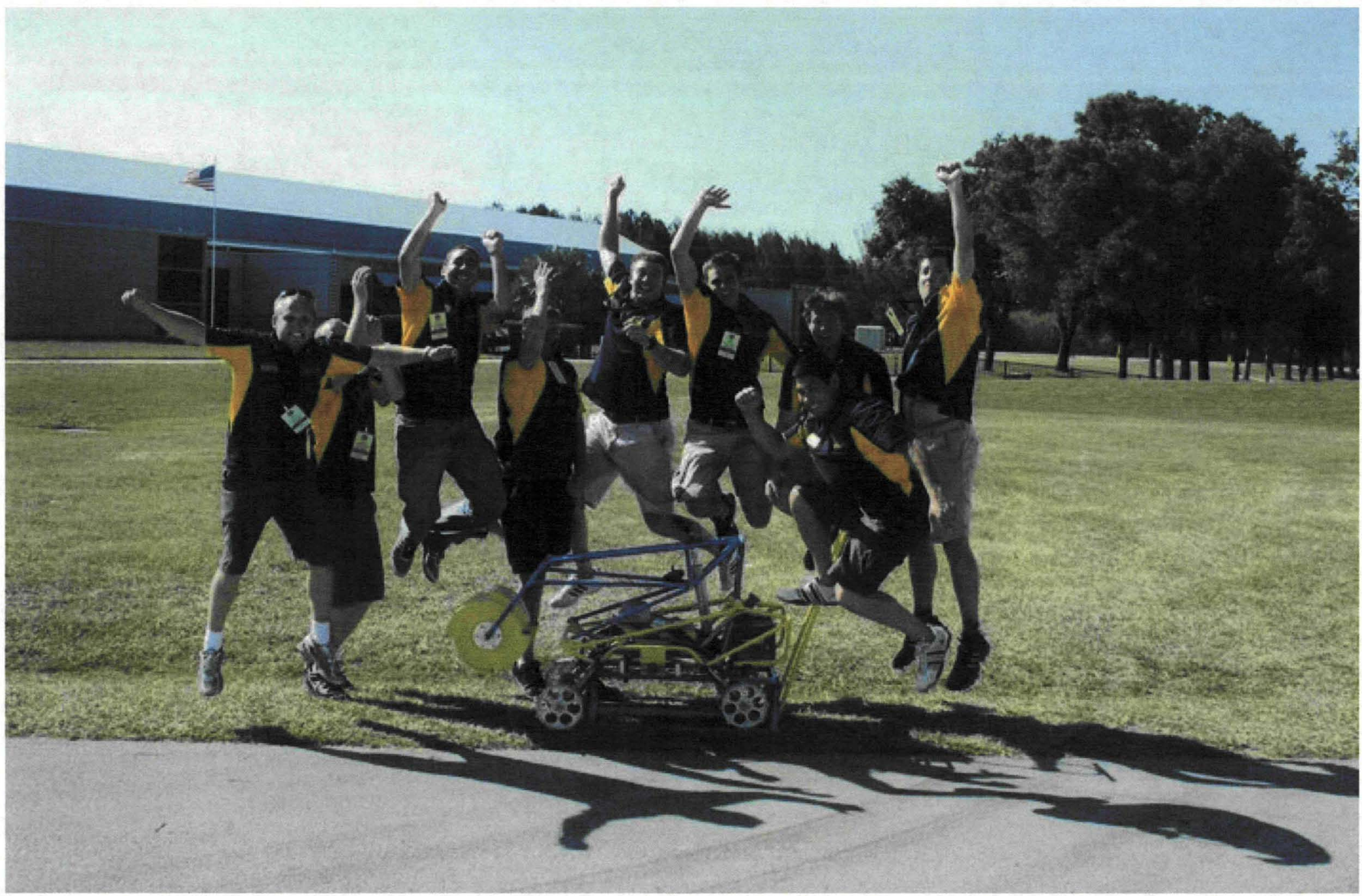




\section{New Judging Criteria for Lunabotics: 2012}

\begin{tabular}{|c|c|c|c|c|}
\hline Mining Category Elements & $\begin{array}{l}\text { Specific } \\
\text { Points }\end{array}$ & Actual & Units & LunaPoints \\
\hline Pass Inspections & & & & 1000 \\
\hline Regolith over 10 kg & $+2 / \mathrm{kg}$ & 110 & $\mathrm{~kg}$ & +200 \\
\hline Average Bandwidth & $-1 / 50 \mathrm{~kb} / \mathrm{sec}$ & 5000 & $\mathrm{~kb} / \mathrm{sec}$ & -100 \\
\hline Lunabot Mass & $-10 / \mathrm{kg}$ & 80 & $\mathrm{~kg}$ & -800 \\
\hline Report Energy Consumed & +100 & 1 & $\begin{array}{l}\text { 1= Achieved } \\
0=\text { Not } \\
\text { Achieved }\end{array}$ & +100 \\
\hline $\begin{array}{l}\text { Dust Tolerant Design \& } \\
\text { Dust Free Operation }\end{array}$ & 0 to +200 & 150 & \begin{tabular}{|l} 
Judges' \\
Decision
\end{tabular} & +150 \\
\hline $\begin{array}{l}\text { Autonomy through } \\
\text { Obstacles }\end{array}$ & +250 & 0 & $\begin{array}{l}\text { 1= Achieved } \\
0=\text { Not } \\
\text { Achieved } \\
\end{array}$ & 0 \\
\hline Full Autonomy & +500 & 0 & $\begin{array}{l}1=\text { Achieved } \\
0=\text { Not } \\
\text { Achieved }\end{array}$ & 0 \\
\hline \multicolumn{4}{|l|}{ Total } & 550 \\
\hline
\end{tabular}


Various competitions during the last five years have demonstrated that STEM inspiration is possible and successful with lunar regolith excavation competitions.

- Students are drawn to the real nature of the task, and industrial partners have expressed a high degree of interest in employing engineers with the mechatronic skills needed to build a lunabot system.

The future is bright for these types of competitions and the Lunabotics Mining Competition is planned to be held annually to meet this demand for exciting challenges, that result in superior engineering solutions and personal growth.

NASA and the nation will benefit by having a better workforce and a plethora of clever ideas to investigate for future space exploration missions. 
Education Lead, Mr. Jerry Hartman who has been instrumental to the success of these competitions in 2010 and 2011.

Mr. Robert Cabana, Center Director of KSC was highly supportive of hosting this competition and provided inspiration to hundreds of students.

In addition, outstanding project management was provided by Ms. Gloria Murphy, at NASA KSC who is the ESMD Space Grant Manager \& Lunabotics Mining Competition Project Manager. Ms. Susan Sawyer provided coordination for all aspects of the events and served as the interface between the student teams and NASA and is highly commended for the dedication and efficiency provided in planning and daily operations.

The Centennial Challenges Lunar Excavation Competition was managed by Mr. Ken Davidian and Mr. Andrew Petro in the Innovative Partnerships Program (IPP) office at NASA HQ and brought to a successful conclusion with a \$500,000 prize awarded in 2009.

We would also like to thank our industrial sponsors for the NASA Lunabotics Mining Competition as listed below:

Delaware North, Kennedy Space Center Visitor's Center

- Caterpillar inc.

- Newmont Mining

- Harris Corp.

- Honeybee Robotics SpaceCraft Mechanisms

- American Institute of Aeronautics and Astronautics (AIAA) Space Resources Technical Committee

- American Society of Civil Engineers (ASCE) Regolith Operations, Mobility and Robotics Technical Committee 